\title{
Artificial intelligence and guidance of medicine in the bubble
}

\author{
Asma Akbar ${ }^{1,2}$, Nagavalli Pillalamarri', Sriya Jonnakuti ${ }^{1}$ and Mujib Ullah ${ }^{1,2^{*}}$ (D)
}

\begin{abstract}
Microbubbles are nanosized gas-filled bubbles. They are used in clinical diagnostics, in medical imaging, as contrast agents in ultrasound imaging, and as transporters for targeted drug delivery. They can also be used to treat thrombosis, neoplastic diseases, open arteries and vascular plaques and for localized transport of chemotherapies in cancer patients. Microbubbles can be filled with any type of therapeutics, cure agents, growth factors, extracellular vesicles, exosomes, miRNAs, and drugs. Microbubbles protect their cargo from immune attack because of their specialized encapsulated shell composed of lipid and protein. Filled with curative medicine, they could effectively circulate through the whole body safely and efficiently to reach the target area. The advanced bubble-based drug-delivery system, integrated with artificial intelligence for guidance, holds great promise for the targeted delivery of drugs and medicines.
\end{abstract}

Keywords: Artificial intelligence, Microbubbles, Nano-vesicles, Drug transportation, Targeted therapies

\section{Introduction}

Many drugs and medicines are susceptible to degradation, which makes it challenging to formulate them and deliver them to specific targets $[1,2]$. The chemistry of these drugs makes the process even more challenging because it can lead to nonspecific side effects, interrupt normal physiology of intracellular receptors, damage healthy tissues, and result in unguided delivery [2-4]. Additionally, these drugs have reduced permeation across biological barriers, affinity towards unspecific sites, and a tendency to unload chemicals to multiple healthy targets [3]. To overcome these shortcomings, microbubbles deliver their cargo to molecular sites of disease while being tracked in real time by the latest simulation of artificial intelligence $[3,5,6]$.

AI could potentially enhance the effectiveness of microbubble technology [6-8]. Bubbles guided by AI, and the

\footnotetext{
*Correspondence: ullah@stanford.edu

${ }^{1}$ Institute for Immunity and Transplantation, Stem Cell Biology

and Regenerative Medicine, School of Medicine, Stanford University, Palo Alto, CA 94304, USA

Full list of author information is available at the end of the article
}

medicine they encapsulate, have the power to improve the visualization of cardiac disease, which will give new life to the field of echocardiography or focused ultrasound imaging of the heart [9-12]. They are routinely used to evaluate myocardial perfusion and heart function and in kidney dialysis [11, 12]. Clinically, microbubbles are established for routine screening of a range of diseases, including cancer, cancerous lesions, inflammatory processes, cardiovascular pathologies, and diseases associated with aging, Table 1 [12-15].

Molecular imaging is an advanced way for decoding the biological processes to visualize and reveal the cellular events at molecular level $[16,17]$. For example, quantum dots are photostable for longer duration and enhance the imaging of deep tissues [17]. Similarly, the fluorescence imaging with indocyanine green based system is valuable for monitoring of surgical procedures [17, 18]. Magnetic resonance imaging is clinically applied to visualize and expose the structural and pathological changes [19, 20]. Combination of different nanoparticles and contrast agents makes the field of molecular imaging more appealing for clinical applications [21-23]. The process of molecular imaging can be clinically improved by

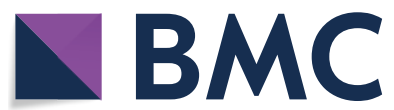

(c) The Author(s) 2021. This article is licensed under a Creative Commons Attribution 4.0 International License, which permits use, sharing, adaptation, distribution and reproduction in any medium or format, as long as you give appropriate credit to the original author(s) and the source, provide a link to the Creative Commons licence, and indicate if changes were made. The images or other third party material in this article are included in the article's Creative Commons licence, unless indicated otherwise in a credit line to the material. If material is not included in the article's Creative Commons licence and your intended use is not permitted by statutory regulation or exceeds the permitted use, you will need to obtain permission directly from the copyright holder. To view a copy of this licence, visit http://creativeco mmons.org/licenses/by/4.0/. The Creative Commons Public Domain Dedication waiver (http://creativecommons.org/publicdomain/ zero/1.0/) applies to the data made available in this article, unless otherwise stated in a credit line to the data. 


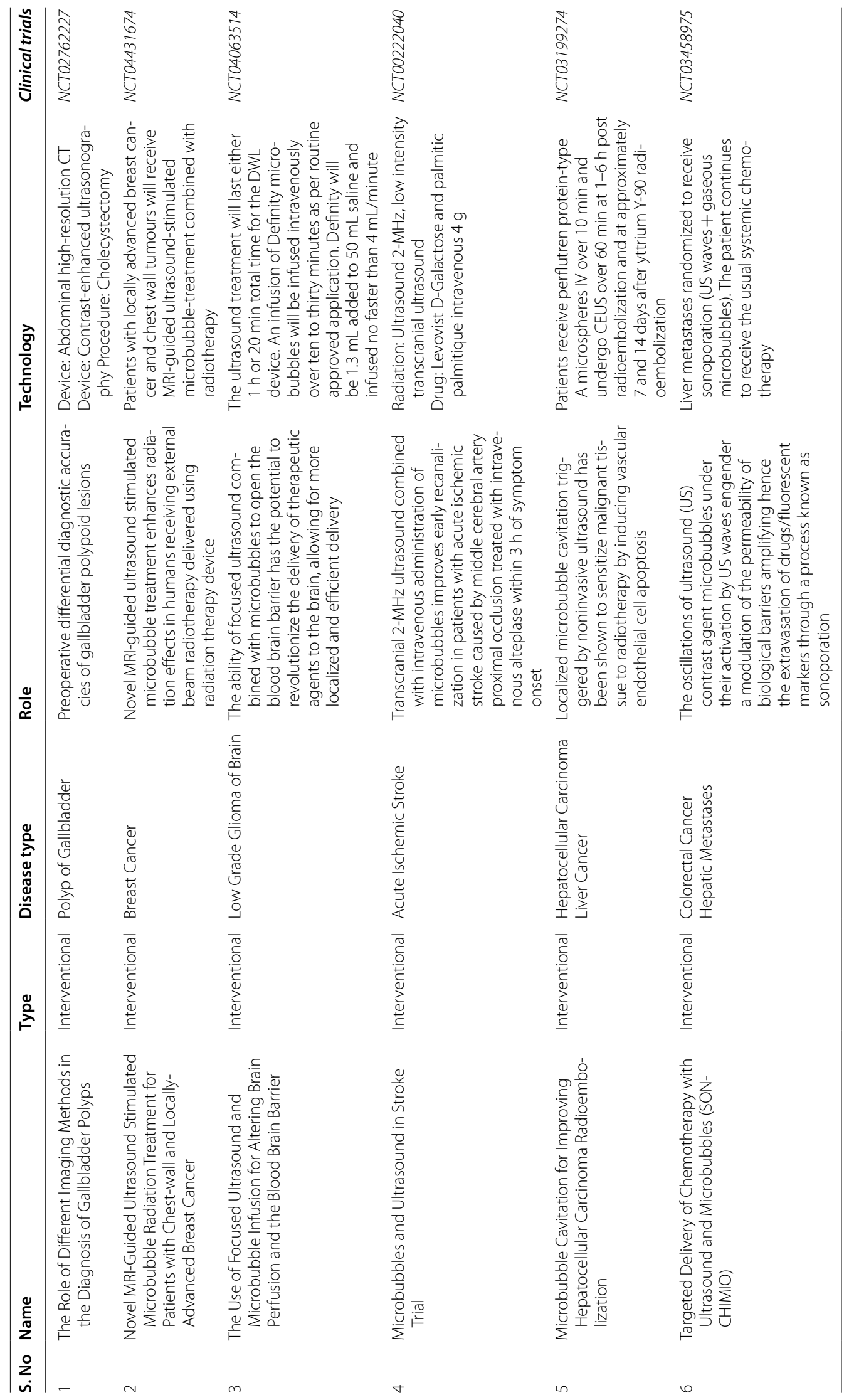


designing and engineering of new class of contrast agents, which are more sensitive, targeted, non-toxic and precise for molecular identification [24-26]. Such as monoclonal antibodies, nanoprobes, quantum dots, molecular dyes, and other targeting signatures are routinely attached to the surface of microbubble and extracellular vesicles for clinical monitoring of treatment process $[5,14,21,22$, 26 ,27]. Therapeutic drugs and medicines include growth factors, antibodies, peptides and recombinant proteins; microbubbles increase the effectiveness, specificity, and potency of these therapeutics [28-30].

\section{The role of guided microbubbles in different diseases}

Conventional medicine are known for their shortcomings such as toxicity to healthy tissues, not very specific to the targets, do not have the ability to cross the blood brain barrier, and have other side effects which restrict their applications [9, 31, 32]. New technologies have significantly improved the perspective of precision medicine [33-35]. The smart approach of using microbubbles loaded with degradable loaded drugs have the potential to deliver the medicine precisely to the targets where it is needed [36, 37]. Precision medicine (such as guided microbubbles) use the high throughput knowledge and artificial intelligence to enhance the process of clinical diagnosis and treatment [38, 39]. Moreover, the precision approach can also be used for preventive and surveillance measures of diseases. treatment efficiency and real time monitoring of drugs [39, 40]. Microbubbles loaded with drug are guided carriers that deliver medicine to targeted sites [2, 30, 41]. These bubbles increase the localized drug concentration at the site of disease, and mimicking the toxicity and unwanted delivery to healthy tissues and surrounding microenvironment [41, 42]. Ultrasound-guided microbubbles are routinely used in the treatment of many diseases' such as cardiovascular disorders including thrombolysis, in the clinical imaging of tumor sites, and diagnosis of cancer and therapeutics [42-44]. Studies have shown that microbubbles loaded with drugs (such as growth factors, precision medicine, tissue plasminogen activator (tPA), regenerative molecules, and imaging probes) have improved the clinical outcome in different diseases $[45,46]$. Microbubbles loaded with tPA successfully dissolved blood clots precisely at the tissue target sites, and bubbles loaded with regenerative cargo improved the healing effects in tissues repair process [42-44, 47]. Technology-guided microbubbles are well studied for targeted release of drugs at inflammatory and tumor sites Fig. 1 [3, 48]. Monoclonal antibodies, cytokines, tumor inhibitors, chimeric antigen receptor $\mathrm{T}$ cells therapies, and clinical chemotherapeutic drugs (for example, 5-fluorouracil and doxycycline) have

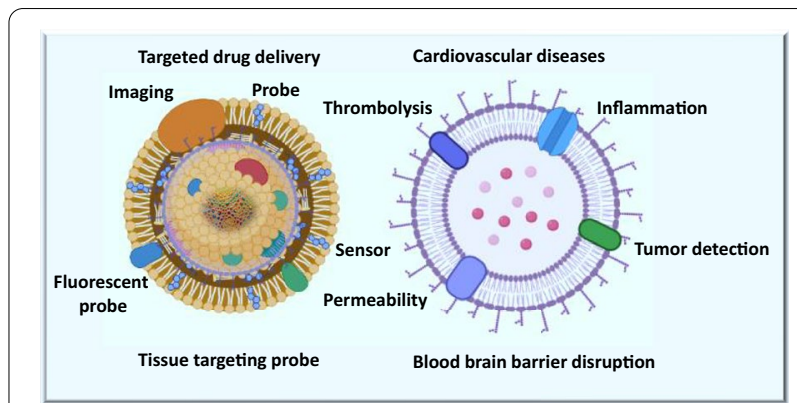

Fig. 1 Role of guided microbubbles in drug delivery and imaging and in different diseases

successfully been loaded into microbubbles and applied in the treatment of neck, breast, pancreatic, ovarian, and hepatocellular carcinoma [49-51]. Ultrasound-targeted microbubbles have already been validated as an effective method for delivering microRNAs to tumor sites in clinical treatment of human malignancies [38, 49].

AI could be used for medical imaging, patient monitoring, and for the targeted release of drugs at the damaged sites. It will enhance the therapeutic efficiency by increasing the localized drug concentration at diseased sites [8]. Microbubbles can cross the blood-brain barrier, meaning drugs can reach any brain cell in a targeted manner [8]. Microbubbles loaded with glial cell-derived neurotrophic factor (GDNF) and brain-derived neurotrophic factor (BDNF) have been shown to specifically accelerate the cell survival of dopaminergic neurons and protect neurons in treatment of many diseases, such as stroke, Alzheimer's, Parkinson's disease, seizure disorders, brain or spinal injuries, and other neurological disorders $[8,15,44,52-54]$. Ultrasound has the potential for activation of drug release at targeted regions, and has the ability of precise-imaging to identify the diseased sites, thus enhancing the implications of microbubbles in treatment of different diseases $[44,55]$. This technology includes the potential to monitor the drug and treatment response in real time, which increases the effectiveness of this approach Figs. 1, 2 and 3.

\section{Technology and microbubbles}

The technology behind the smart design of microbubbles has attracted great attention due to its wide application in many fields of science and technology [21, 56]. The nano-sized microbubbles are negatively charged $[56,57]$. Particles with positive charges, known as free radicals, engulf electrons from healthy cells to neutralize their own charge, causing cellular damage $[15,58,59]$. In contrast, negatively charged bubbles fight free radicals to improve the health of damaged cells and detoxify the inflammatory fluids in diseased tissue $[15,60]$. 


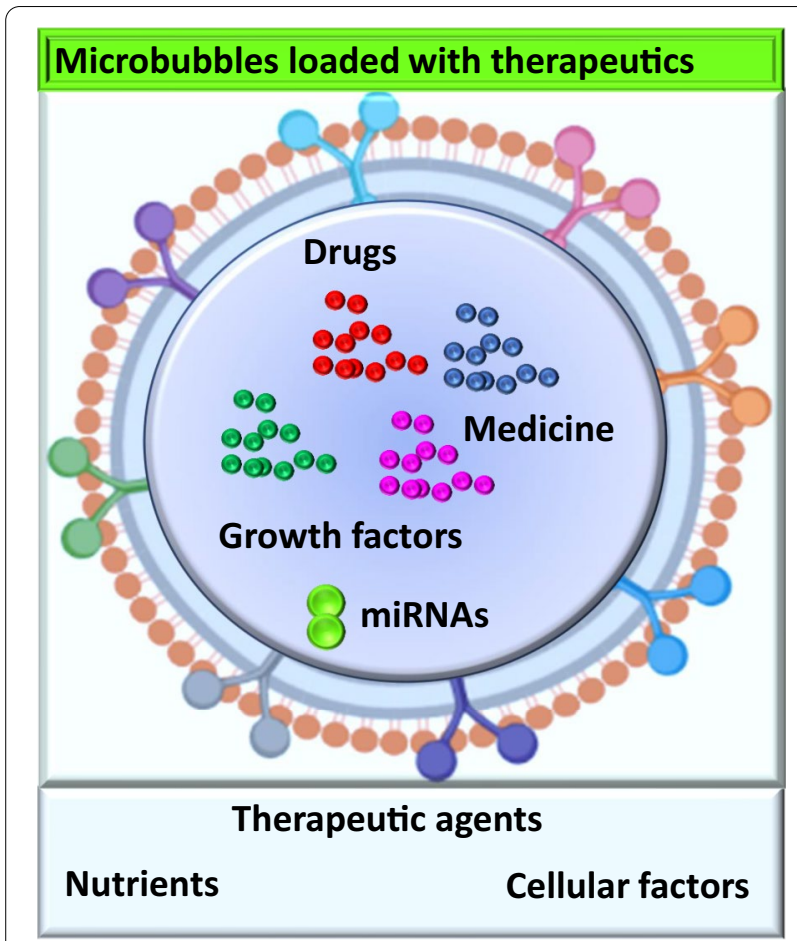

Fig. 2 Microbubbles and loaded therapeutic cargo

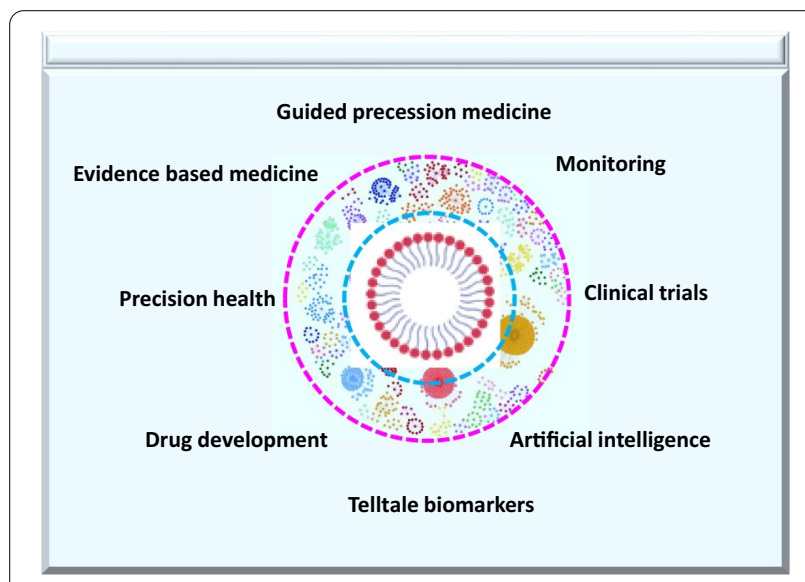

Fig. 3 Guided microbubbles and technology

Microbubbles newly designed through biomedical engineering and nanomaterials approaches are crucial for intracellular delivery of proteins, drugs, growth factors, and peptides, Fig. 2 [9, 30, 42]. They may revolutionize the whole biopharmaceutical drug industry $[14,58]$. Although technological breakthroughs have been made in the development, monitoring, and tracking of drugs by artificial intelligence and in the delivery of biopharmaceutical drugs, challenges and unanswered questions remain [61]. The medicine in the bubbles can target both extracellular and intracellular targets and guide the localized drug delivery to specific sites [61].

\section{Medicine and the machine}

Artificial intelligence (AI)-based technologies have the potential to transform the healthcare industry by deriving innovative approaches to the discovery of drugs, Fig. 3 [5, 61]. Examples of innovation through AI range from self-driving cars to pattern- and image-recognition tools to clinical diagnostics that allow expedited drug discovery, earlier detection of disease, more precise diagnosis, identification of new biomarkers, and development of personalized diagnostics and therapeutics $[6,7,10,62]$. $\mathrm{AI}$ has the power to treat, diagnose, cure, mitigate, or prevent disease or other critical or serious conditions [29, $61,63]$. Recent studies have shown that AI can expedite diabetic retinopathy and eye scan $[29,61,63,64]$. AI has incredible pattern-recognizing abilities within big data and thus holds the potential to solve many key clinical challenges [64]. Leveraging AI with microbubble technology may expedite and enhance early detection of disease and patient care [5, 62].

\section{Medicine in microbubbles and the blood-brain barrier}

The blood-brain barrier (BBB) is responsible for protection against circulating toxins, preventing harmful pathogens from entering the brain $[44,65]$. The defensive wall of the BBB prevents brain infections, but it also blocks medicines that could treat brain diseases, neurological disorders, and neurodegenerative diseases [44, 65, 66]. This protective wall presents an obstacle for most of the available drugs in the market $[66,67]$. Medicine in microbubbles, in contrast, can reach and open the BBB to target the disease site effectively instead of circulating randomly in the system $[67,68]$. The brain is the only organ known to have its own security system; however, medicine in the bubbles breaks the defensive wall of the $\mathrm{BBB}$ and allows lifesaving drugs to reach their targets to repair the injured or diseased brain [68]. Usually drugs are chemicals, and the brain senses these harsh molecules and blocks its defensive door using the BBB; however, medicines in bubbles are difficult to interpret as chemicals or dangerous enemies as they are encapsulated in a shell, Figs. 1, 2 and 3 [15, 53, 66, 68].

\section{Conclusion}

Microbubbles have the potential to protect their cargo from degradation, restrict the drug release to disease sites, and prevent nonspecific drug delivery to healthy tissues [69, 70]. Medicine in bubbles enhances targeted drug delivery, tumor targeting, ultrasound imaging, and intracellular drug release $[7,71]$. These microbubbles 
can be used for the delivery of oxygen in stroke patients, and delivery of immune cells in those patients who has weak immune system [54, 72, 73]. AI-powered capabilities, including data integration and interpretation, are fundamental for clinical transformation of microbubbles to enhance treatment efficacy $[7,38]$. Leveraging technology will enhance the ability of microbubbles and extracellular vesicles for oxygen release to energizes cells and stimulates the immune system against different diseases $[74,75]$. Ultrasound guided microbubbles can be used for opening blocked arteries, for increasing the permeability of blood brain barrier and drug delivery to those tissues which are otherwise difficult target for conventional drug delivery [76-78].

The delivery of medicine in bubbles has some limitations, such as undesired shell cracking due to acoustic pressure, limited capacity for drug loading and cavitation in the ultrasound field $[30,61]$. The biostability of microbubbles is poor in some organs, less biocompatible, structurally unstable, and limited circulation time in certain tissues. Sometimes these bubbles have difficulty reaching deep and hard ossified tissues [30, 38]. The safety, ethics, effectiveness, and functionality of the process should be considered to improve the development of next generation of microbubbles with innovative engineering approaches to enhance the drug loading capacity of bubbles [21, 79-81]. Designing of bubbles for precise imaging should revolutionize the field of molecular imaging and precision medicine for treatment of cancer, aging, cardiovascular and neurological diseases [13, 30, 82].

Microbubbles are inert, nonreactive vesicles which makes them ideal for molecular imaging, bypassing microcirculation, and ideal cargo for conventionally challenged targets [83-85]. Although there are still some challenges in the clinical translation, but scientists are expecting that newly designed microbubbles can be leveraged to AI methods and techniques [86, 87]. These emerging bubbles can be used to train neural networks and other tissues and to monitor drugs for real time imaging and precise treatment [87-89]. Microbubbles with integrated molecular sensor-probes have the ability to distinguish contrast agents and differentiate healthy versus diseased sites $[90,91]$. The technological platform of microbubbles applications should be upgraded with $\mathrm{AI}$ integration for more safer, and real-time tracking of drugs in clinical translation [92]. Further research of guided microbubbles is needed to explore the field drug delivery. The field of bioengineering for designing smart microbubbles will revolutionize this technology further, which has already been shown its role in real time molecular imaging and precise treatment of different diseases such as cardiovascular and neurological disorders [93,
94]. The integration of $\mathrm{AI}$ and other technologies in the field of microbubbles will accelerate the development of strategies for detection, prevention, diagnosis, treatment, and cure.

\section{Abbreviations}

EVs: Extracellular vesicles; BDNF: Brain-derived neurotrophic factor; GDNF: Glial cell line-derived neurotrophic factor; BBB: Blood-brain barrier.

\section{Acknowledgements}

The schematic representations were designed in the Adobe Illustrator. We also used the support of ChemDraw (PerkinEImer Informatics) and Biorender (@BioRender-biorender.com) for combination figures.

\section{Authors' contributions}

MU: Conceptualization, data mining, coordinated the project and wrote the paper, MU, NP, AA, SJ: Data analysis and writing of review manuscript. MU, NP, SJ, and AA: Conceptualization, manuscript review, editing suggestions, and final approval. All authors read and approved the final manuscript.

\section{Funding}

None.

Availability of data and materials

Not applicable.

\section{Declarations}

Ethics approval and consent to participate

Not applicable.

\section{Consent for publication}

The data is original for this article and the sources used have been cited both within the article and within the Figures.

\section{Competing interests}

The authors declare that they have no competing interests.

\section{Author details}

${ }^{1}$ Institute for Immunity and Transplantation, Stem Cell Biology and Regenerative Medicine, School of Medicine, Stanford University, Palo Alto, CA 94304, USA. ${ }^{2}$ Molecular Medicine, Department of Biomedical Innovation and Bioengineering, School of Medicine, Stanford University, Palo Alto, CA, USA.

Received: 16 March 2021 Accepted: 4 June 2021

Published online: 09 June 2021

\section{References}

1. Bobo D, Robinson KJ, Islam J, Thurecht KJ, Corrie SR. Nanoparticle-based medicines: a review of FDA-approved materials and clinical trials to date. Pharm Res. 2016;33(10):2373-87.

2. Blessy M, Patel RD, Prajapati PN, Agrawal YK. Development of forced degradation and stability indicating studies of drugs-a review. J Pharm Anal. 2014;4(3):159-65.

3. Choonara BF, Choonara YE, Kumar P, Bijukumar D, du Toit LC, Pillay V. A review of advanced oral drug delivery technologies facilitating the protection and absorption of protein and peptide molecules. Biotechnol Adv. 2014;32(7):1269-82.

4. Ullah M. The Pandemic of Novel Coronavirus Disease 2019 (COVID-19): need for an immediate action. Open Access J Biomed Sci. 2020. https:// doi.org/10.38125/OAJBS.000168.

5. Dilsizian SE, Siegel EL. Artificial intelligence in medicine and cardiac imaging: harnessing big data and advanced computing to provide personalized medical diagnosis and treatment. Curr Cardiol Rep. 2014;16(1):441. 
6. Ullah M, Akbar A, Yannarelli G. Applications of artificial intelligence in, early detection of cancer, clinical diagnosis and personalized medicine. Artificial Intelligence Cancer. 2020;1(2):39-44.

7. Jin X, Liu C, Xu T, Su L, Zhang X. Artificial intelligence biosensors: Challenges and prospects. Biosens Bioelectron. 2020;165:112412.

8. Toccaceli G, Barbagallo G, Peschillo S. Low-intensity focused ultrasound for the treatment of brain diseases: safety and feasibility. Theranostics. 2019;9(2):537-9.

9. Rodríguez-Rodríguez J, Sevilla A, Martínez-Bazán C, Gordillo JM. Generation of microbubbles with applications to industry and medicine. Annu Rev Fluid Mech. 2015;47:405-29.

10. Hamet P, Tremblay J. Artificial intelligence in medicine. Metabolism. 2017;69S:S36-40

11. Lindner JR. Therapeutic contrast echocardiography: bubbles become medicine. In: American College of Cardiology Foundation Washington, DC; 2019.

12. Ling ZY, Shu SY, Zhong SG, Luo J, Su L, Liu ZZ, Lan XB, Yuan GB, Zheng YY, Ran HT, et al. Ultrasound targeted microbubble destruction promotes angiogenesis and heart function by inducing myocardial microenvironment change. Ultrasound Med Biol. 2013;39(11):2001-10.

13. Postema M, Schmitz G. Ultrasonic bubbles in medicine: influence of the shell. Ultrason Sonochem. 2007;14(4):438-44.

14. Willmann JK, Paulmurugan R, Chen K, Gheysens O, Rodriguez-Porcel M, Lutz AM, Chen IY, Chen X, Gambhir SS. US imaging of tumor angiogenesis with microbubbles targeted to vascular endothelial growth factor receptor type 2 in mice. Radiology. 2008;246(2):508-18.

15. Tung YS, Marquet F, Teichert T, Ferrera V, Konofagou EE. Feasibility of noninvasive cavitation-guided blood-brain barrier opening using focused ultrasound and microbubbles in nonhuman primates. Appl Phys Letters. 2011;98(16):163704.

16. Ullah M, Kodam SP, Mu Q, Akbar A. Microbubbles versus extracellular vesicles as therapeutic cargo for targeting drug delivery. ACS Nano. 2021;15(3):3612-20.

17. Liu Q, Guo B, Rao Z, Zhang B, Gong JR. Strong two-photon-induced fluorescence from photostable, biocompatible nitrogen-doped graphene quantum dots for cellular and deep-tissue imaging. Nano Lett. 2013;13(6):2436-41.

18. Terasawa M, Ishizawa T, Mise $Y$, Inoue $Y$, Ito H, Takahashi $Y$, Saiura A. Applications of fusion-fluorescence imaging using indocyanine green in laparoscopic hepatectomy. Surv Methodol. 2017;31(12):5111-8.

19. Alhadlaq HA, Xia Y, Moody JB, Matyas JR. Detecting structural changes in early experimental osteoarthritis of tibial cartilage by microscopic magnetic resonance imaging and polarised light microscopy. Ann Rheum Dis. 2004;63(6):709-17.

20. Morris MF, Verma DR, Sheikh H, Su W, Pershad A. Outcomes after magnetic resonance imaging in patients with pacemakers and defibrillators and abandoned leads. Cardiovasc Revasc Med. 2018;19(6):685-8.

21. Hettiarachchi K, Talu E, Longo ML, Dayton PA, Lee AP. On-chip generation of microbubbles as a practical technology for manufacturing contrast agents for ultrasonic imaging. Lab Chip. 2007;7(4):463-8.

22. Wilson SR, Burns PN. Microbubble-enhanced US in body imaging: what role? Radiology. 2010;257(1):24-39.

23. Hahn MA, Singh AK, Sharma P, Brown SC, Moudgil BM. Nanoparticles as contrast agents for in-vivo bioimaging: current status and future perspectives. Anal Bioanal Chem. 2011;399(1):3-27.

24. James ML, Gambhir SS. A molecular imaging primer: modalities, imaging agents, and applications. Physiol Rev. 2012;92(2):897-965.

25. Egerton A, Mehta MA, Montgomery AJ, Lappin JM, Howes OD, Reeves SJ, Cunningham VJ, Grasby PM. The dopaminergic basis of human behaviors: A review of molecular imaging studies. Neurosci Biobehav Rev. 2009;33(7):1109-32.

26. Weissleder R. Molecular imaging: exploring the next frontier. Radiology. 1999;212(3):609-14.

27. Wong FC, Kim EE. A review of molecular imaging studies reaching the clinical stage. Eur J Radiol. 2009;70(2):205-11.

28. Ullah M, Qiao Y, Concepcion W, Thakor AS. Stem cell-derived extracellular vesicles: role in oncogenic processes, bioengineering potential, and technical challenges. Stem Cell Res Ther. 2019;10(1):347.

29. Feng $R, Y u F, X u J$, Hu X. Knowledge gaps in immune response and immunotherapy involving nanomaterials: databases and artificial intelligence for material design. Biomaterials. 2021;266:120469.
30. Chang S, Si T, Zhang S, Merrick MA, Cohn DE, Xu RX. Ultrasound mediated destruction of multifunctional microbubbles for image guided delivery of oxygen and drugs. Ultrason Sonochem. 2016;28:31-8.

31. Rudin M, Weissleder R. Molecular imaging in drug discovery and development. Nat Rev Drug Discov. 2003;2(2):123-31.

32. Waterhouse RN. Determination of lipophilicity and its use as a predictor of blood-brain barrier penetration of molecular imaging agents. $\mathrm{Mol}$ Imag Biol. 2003;5(6):376-89.

33. Ghasemi M, Nabipour I, Omrani A, Alipour Z, Assadi M. Precision medicine and molecular imaging: new targeted approaches toward cancer therapeutic and diagnosis. Am J Nucl Med Mol Imaging. 2016;6(6):310-27.

34. Penet MF, Krishnamachary B, Chen Z, Jin J, Bhujwalla ZM. Molecular imaging of the tumor microenvironment for precision medicine and theranostics. Adv Cancer Res. 2014;124:235-56.

35. Ullah M, Akbar A. Clinical relevance of RNA editing to early detection of cancer in human. Int J Stem Cell Res Ther. 2020;7(1):66.

36. Fiordelisi MF, Auletta L, Meomartino L, Basso L, Fatone G, Salvatore M, Mancini M, Greco A. Preclinical molecular imaging for precision medicine in breast cancer mouse models. Contrast Media Mol Imaging. 2019;2019:8946729.

37. Gao Z, Kennedy AM, Christensen DA, Rapoport NY. Drug-loaded nano/ microbubbles for combining ultrasonography and targeted chemotherapy. Ultrasonics. 2008;48(4):260-70.

38. Kondo S, Takagi K, Nishida M, Iwai T, Kudo Y, Ogawa K, Kamiyama T, Shibuya H, Kahata K, Shimizu C. Computer-aided diagnosis of focal liver lesions using contrast-enhanced ultrasonography with perflubutane microbubbles. IEEE Trans Med Imaging. 2017;36(7):1427-37.

39. Zhu JQ, Rowland EM, Harput S, Riemer K, Leow CH, Clark B, Cox K, Lim A, Christensen-Jeffries K, Zhang G, et al. 3D Super-resolution US imaging of rabbit lymph node vasculature in vivo by using microbubbles. Radiology. 2019;291(3):642-50.

40. de Senneville BD, Frulio N, Laumonier H, Salut C, Lafitte L, Trillaud H. Liver contrast-enhanced sonography: computer-assisted differentiation between focal nodular hyperplasia and inflammatory hepatocellular adenoma by reference to microbubble transport patterns. Eur Radiol. 2020;30(5):2995-3003.

41. Sirsi SR, Hernandez SL, Zielinski L, Blomback H, Koubaa A, Synder M, Homma S, Kandel JJ, Yamashiro DJ, Borden MA. Polyplex-microbubble hybrids for ultrasound-guided plasmid DNA delivery to solid tumors. J Control Release. 2012;157(2):224-34

42. de Saint VM, Crake C, Coussios CC, Stride E. Properties, characteristics and applications of microbubbles for sonothrombolysis. Expert Opin Drug Deliv. 2014;11(2):187-209.

43. Tsivgoulis G, Culp WC, Alexandrov AV. Ultrasound enhanced thrombolysis in acute arterial ischemia. Ultrasonics. 2008;48(4):303-11.

44. Hynynen K, Clement G. Clinical applications of focused ultrasound-the brain. Int J Hyperthermia. 2007;23(2):193-202.

45. Yan WC, Chua QW, Ong XJ, Sharma VK, Tong YW, Wang CH. Fabrication of ultrasound-responsive microbubbles via coaxial electrohydrodynamic atomization for triggered release of tPA. J Colloid Interface Sci. 2017:501:282-93.

46. Wu J, Xie F, Lof J, Sayyed S, Porter TR. Utilization of modified diagnostic ultrasound and microbubbles to reduce myocardial infarct size. Heart. 2015;101(18):1468-74.

47. Hua X, Zhou L, Liu P, He Y, Tan K, Chen Q, Gao Y, Gao Y. In vivo thrombolysis with targeted microbubbles loading tissue plasminogen activator in a rabbit femoral artery thrombus model. J Thromb Thrombolysis. 2014;38(1):57-64

48. Escoffre J-M, Deckers R, Bos C, Moonen C. Bubble-assisted ultrasound: application in immunotherapy and vaccination. In: Therapeutic Ultrasound. Springer; 2016, p. 243-61.

49. Abed Z, Khoei S, Ghalandari B, Beik J, Shakeri-Zadeh A, Ghaznavi H, Shiran $M B$. The measurement and mathematical analysis of 5-Fu release from magnetic polymeric nanocapsules, following the application of ultrasound. Anticancer Agents Med Chem. 2018;18(3):438-49.

50. Ullah M, Akbar A, Ng NN, Concepcion W, Thakor AS. Mesenchymal stem cells confer chemoresistance in breast cancer via a CD9 dependent mechanism. Oncotarget. 2019;10(37):3435-50.

51. Ullah M, Akbar A, Thakor AS. An emerging role of CD9 in stemness and chemoresistance. Oncotarget. 2019;10(40):4000-1. 
52. Burgess MT, Apostolakis I, Konofagou EE. Power cavitation-guided bloodbrain barrier opening with focused ultrasound and microbubbles. Phys Med Biol. 2018;63(6):065009.

53. Lipsman N, Meng Y, Bethune AJ, Huang YX, Lam B, Masellis M, Herrmann N, Heyn C, Aubert I, Boutet A, et al. Blood-brain barrier opening in Alzheimer's disease using MR-guided focused ultrasound. Nat Commun. 2018;9(1):1-8

54. Rodriguez-Frutos B, Otero-Ortega L, Ramos-Cejudo J, Martinez-Sanchez P, Barahona-Sanz I, Navarro-Hernanz T, Gomez-de FrutosMdel C, DiezTejedor E, Gutierrez-Fernandez M. Enhanced brain-derived neurotrophic factor delivery by ultrasound and microbubbles promotes white matter repair after stroke. Biomaterials. 2016;100:41-52.

55. Huynh E, Lovell JF, Helfield BL, Jeon M, Kim C, Goertz DE, Wilson BC, Zheng G. Porphyrin shell microbubbles with intrinsic ultrasound and photoacoustic properties. J Am Chem Soc. 2012;134(40):16464-7.

56. Lin H, Chen J, Chen C. A novel technology: microfluidic devices for microbubble ultrasound contrast agent generation. Med Biol Eng Comput. 2016;54(9):1317-30.

57. Delalande A, Postema M, Mignet N, Midoux P, Pichon C. Ultrasound and microbubble-assisted gene delivery: recent advances and ongoing challenges. Ther Deliv. 2012;3(10):1199-215.

58. Abdalkader R, Kawakami S, Unga J, Suzuki R, Maruyama K, Yamashita F, Hashida M. Evaluation of the potential of doxorubicin loaded microbubbles as a theranostic modality using a murine tumor model. Acta Biomater. 2015;19:112-8.

59. Chertok B, Langer R. Circulating magnetic microbubbles for localized real-time control of drug delivery by ultrasonography-guided magnetic targeting and ultrasound. Theranostics. 2018;8(2):341-57.

60. Ullah M. Novel Coronavirus (COVID-19) treatment options. Biomed J Sci Tech Res. 2020;27(3):20872-4.

61. Fleming $\mathrm{N}$. How artificial intelligence is changing drug discovery. Nature. 2018;557(7706):S55-S55.

62. Zhu H. Big data and artificial intelligence modeling for drug discovery. Annu Rev Pharmacol Toxicol. 2020;60:573-89.

63. Hassanzadeh P, Atyabi F, Dinarvand R. The significance of artificial intelligence in drug delivery system design. Adv Drug Deliv Rev. 2019;151-152:169-90.

64. Winkler-Schwartz A, Bissonnette V, Mirchi N, Ponnudurai N, Yilmaz R, Ledwos N, Siyar S, Azarnoush H, Karlik B, Del Maestro RF. Artificial intelligence in medical education: best practices using machine learning to assess surgical expertise in virtual reality simulation. J Surg Educ. 2019;76(6):1681-90

65. Pardridge WM. Blood-brain barrier delivery. Drug Discov Today. 2007;12(1-2):54-61.

66. Kreuter J. Mechanism of polymeric nanoparticle-based drug transport across the blood-brain barrier (BBB). J Microencapsul. 2013:30(1):49-54

67. McDannold N, Arvanitis CD, Vykhodtseva N, Livingstone MS. Temporary disruption of the blood-brain barrier by use of ultrasound and microbubbles: safety and efficacy evaluation in rhesus macaques. Can Res. 2012;72(14):3652-63.

68. Tung YS, Vlachos F, Feshitan JA, Borden MA, Konofagou EE. The mechanism of interaction between focused ultrasound and microbubbles in blood-brain barrier opening in mice. J Acoust Soc Am. 2011;130(5):3059-67.

69. Pillalamarri N, Ren G, Khan L, Ullah A, Jonnakuti S, Ullah M. Exploring the utility of extracellular vesicles in ameliorating viral infection-associated inflammation, cytokine storm and tissue damage. Transl Oncol. 2021;14(7):101095.

70. He Y, Zhang B, Chen Y, Jin Q, Wu J, Yan F, Zheng H. Image-guided hydrogen gas delivery for protection from myocardial ischemia-reperfusion injury via microbubbles. ACS Appl Mater Interfaces. 2017;9(25):21190-9.

71. Park Jl, Jagadeesan D, Williams R, Oakden W, Chung S, Stanisz GJ, Kumacheva E. Microbubbles loaded with nanoparticles: a route to multiple imaging modalities. ACS Nano. 2010;4(11):6579-86.

72. Unger E, Porter T, Lindner J, Grayburn P. Cardiovascular drug delivery with ultrasound and microbubbles. Adv Drug Deliv Rev. 2014;72:110-26.

73. Feshitan JA, Legband ND, Borden MA, Terry BS. Systemic oxygen delivery by peritoneal perfusion of oxygen microbubbles. Biomaterials. 2014;35(9):2600-6.
74. Meairs S, Alonso A. Ultrasound, microbubbles and the blood-brain barrier. Prog Biophys Mol Biol. 2007;93(1-3):354-62.

75. Kwan JJ, Kaya M, Borden MA, Dayton PA. Theranostic oxygen delivery using ultrasound and microbubbles. Theranostics. 2012;2(12):1174-84.

76. McEwan C, Owen J, Stride E, Fowley C, Nesbitt H, Cochrane D, Coussios CC, Borden M, Nomikou N, McHale AP, et al. Oxygen carrying microbubbles for enhanced sonodynamic therapy of hypoxic tumours. J Control Release. 2015;203:51-6.

77. Agarwal K, Chatterjee D. The role of encapsulated microbubbles in the diagnosis of stenosis in arteries. In: Journal of Physics: Conference Series: 2015. IOP Publishing: 012002.

78. Zhou XB, Qin H, Li J, Wang B, Wang CB, Liu YM, Jia XD, Shi N. Platelettargeted microbubbles inhibit re-occlusion after thrombolysis with transcutaneous ultrasound and microbubbles. Ultrasonics. 2011;51(3):270-4

79. Li MD, Bussonniere A, Bronson M, Xu ZH, Liu QX. Study of Venturi tube geometry on the hydrodynamic cavitation for the generation of microbubbles. Miner Eng. 2019;132:268-74.

80. Das D, Sivasubramanian K, Yang C, Pramanik M. On-chip generation of microbubbles in photoacoustic contrast agents for dual modal ultrasound/photoacoustic in vivo animal imaging. Sci Rep. 2018;8(1):6401.

81. Zandi A, Khayamian MA, Saghafi M, Shalileh S, Katebi P, Assadi S, Gilani A, SalemizadehParizi M, Vanaei S, Esmailinejad MR, et al. Microneedle-based generation of microbubbles in cancer tumors to improve ultrasoundassisted drug delivery. Adv Healthc Mater. 2019;8(17):e1900613.

82. Feng $\mathrm{R}$, Ullah $\mathrm{M}$, Chen $\mathrm{K}$, Ali Q, Lin Y, Lei H, Sun ZJ. Inducible pluripotent stem cell-derived extracellular vesicles mitigates aging-associated arterial stiffness and hypertension. Circulation. 2017;136(suppl_1):A17570-A17570.

83. Chang LW, Hou ML, Hung SH, Lin LC, Tsai TH. Pharmacokinetics of quercetin-loaded nanodroplets with ultrasound activation and their use for bioimaging. Int J Nanomed. 2015;10:3031-42.

84. López-Marín LM, Rivera AL, Fernández F, Loske AM. Shock wave-induced permeabilization of mammalian cells. Phys Life Rev. 2018;26:1-38.

85. Thakur A, Foged C. Nanoparticles for mucosal vaccine delivery. Nanoeng Biomater Adv Drug Deliv. 2020. https://doi.org/10.1016/B978-0-08102985-5.00025-5.

86. Liu HL, Fan CH, Ting CY, Yeh CK. Combining microbubbles and ultrasound for drug delivery to brain tumors: current progress and overview. Theranostics. 2014;4(4):432-44.

87. Choi JJ, Selert K, Vlachos F, Wong A, Konofagou EE. Noninvasive and localized neuronal delivery using short ultrasonic pulses and microbubbles. Proc Natl Acad Sci USA. 2011;108(40):16539-44.

88. Cui Z, Li D, Feng Y, Xu T, Wu S, Li Y, Bouakaz A, Wan M, Zhang S. Enhanced neuronal activity in mouse motor cortex with microbubbles' oscillations by transcranial focused ultrasound stimulation. Ultrason Sonochem. 2019;59:104745.

89. Scarcelli T, Jordao JF, O'Reilly MA, Ellens N, Hynynen K, Aubert I. Stimulation of hippocampal neurogenesis by transcranial focused ultrasound and microbubbles in adult mice. Brain Stimul. 2014;7(2):304-7.

90. Li F, Li DY, Yan F. Improvement of detection sensitivity of microbubbles as sensors to detect ambient pressure. Sensors. 2018;18(12):4083.

91. Yang Y, Ward J, Chormaic SN. Quasi-droplet microbubbles for high resolution sensing applications. Opt Express. 2014;22(6):6881-98.

92. Kogan P, Gessner RC, Dayton PA. Microbubbles in imaging: applications beyond ultrasound. Bubble Sci Eng Technol. 2010;2(1):3-8.

93. Ullah M, Akbar A, Yannarelli G. Clinical applications of RNA editing technology for the early detection of cancer and future directions. Technol Cancer Res Treat. 2020;19:1533033820964194.

94. Ullah M, Qian NPM, Yannarelli G. Advances in innovative exosometechnology for real time monitoring of viable drugs in clinical translation prognosis and treatment response. Oncotarget. 2021;12(11):1029-31. https://doi.org/10.18632/oncotarget.27927.

\section{Publisher's Note}

Springer Nature remains neutral with regard to jurisdictional claims in published maps and institutional affiliations. 